Federal Reserve Bank of Minneapolis

Research Department Staff Report 274

August 2000

\title{
Risky Collateral and Deposit Insurance
}

\author{
Narayana R. Kocherlakota* \\ University of Minnesota \\ and Federal Reserve Bank of Minneapolis
}

\begin{abstract}
This paper provides a new rationalization for deposit insurance and systemic disintermediations. I consider an environment in which borrowers face no penalty for failing to repay obligations except the loss of their collateral. I assume that this collateral has aggregate risk. For a subset of the exogenous parameters, I demonstrate that an optimal arrangement features deposit insurance. For a strictly smaller set of parameters, it is optimal in some states of the world to have systemic disintermediation and concomitant falls in real output.

*Earlier versions of this paper circulated under the title, "Efficient Institutions of Intermediation." A version of the paper was presented in seminars at the Federal Reserve Bank of Minneapolis, the Texas Monetary Conference, Stanford University, the 1999 SED conference, the Northwestern University Macroeconomics Workshop, the University of Wisconsin, and the University of Washington; I thank the participants in these seminars for their comments. I also thank Harold Cole, Jeff Lacker, Chris Sleet and especially Barbara McCutcheon for their comments. Further comments are welcome; contact the author at nkocher@econ.umn.edu. The views expressed herein are those of the author and not necessarily those of the Federal Reserve Bank of Minneapolis or the Federal Reserve System.
\end{abstract}




\section{Introduction}

In most developed economies, bank loans are explicitly guaranteed by deposit insurance. Why should these loans be guaranteed, while other modes of finance like corporate bonds and stocks are not? In this paper, I focus on one aspect of bank loans that makes them different from other forms of finance: repayment of bank loans is enforced primarily through the use of collateral. I show that if aggregate shocks affect the value of this collateral, then it is optimal to insure owners of bank assets against poor bank loan performance, even when the owners are risk-neutral.

My specific approach is as follows. I construct a simple model economy. In the economy, one group of agents (borrowers) has projects. Another group of agents (lenders) has the resources to operate the projects. The model has three key features. First, it is highly costly to collect resources from the borrowers other than their collateral. Second, the value of the borrowers' collateral may be subject to aggregate shocks. Finally, the lenders can remove any or all of their funds from the projects after they learn the aggregate shock to the borrowers' collateral. I consider the efficient financing and investment arrangements in this model economy.

I demonstrate that these optimal arrangements have three important features. First, if the expost quality of collateral and project returns are known only to the borrower, any optimal repayment contract takes the form of a collateralized debt contract. Second, for a subset of the parameter space, it is optimal to have deposit insurance. Finally, for a strictly smaller subset of the parameter space, it is optimal to have systemic disintermediation (that is, no funding of the borrowers' projects) in some states of the world. For this last set of parameters, the optimal arrangement features fluctuations in aggregate output, even if project returns are deterministic.

The intuition behind the deposit insurance result is simple. Initially, lenders are willing to invest their money in borrowers' projects because they anticipate that the borrowers' collateral is sufficiently good for them to get a good return on their deposits. Then, the lenders see a public 
aggregate shock to the value of the collateral and learn that the collateral's value is lower on average than they expected. Given this observation, the lenders may want to withdraw funding from the projects.

But the shock has not necessarily affected the projects' social return - only the ability of the lenders to share in this social return. This means that from a social point of view, it is optimal to deter the lenders from withdrawing their funds in this situation. Deposit insurance accomplishes this goal by guaranteeing the lenders their return, even when many borrowers default on their loans.

Thus, this paper rationalizes an insurance scheme in which falls in aggregate collateral value trigger large payments from insurers to lenders. Two examples illustrate that this type of insurance appears to be an important component of real-life bailouts of banking systems. During the 1980's in Texas and Louisiana, there were large transfers made from taxpayers to lenders under the aegis of the Federal Savings and Loan Insurance Corporation (and, later, the Resolution Trust Corporation). More recently, the Japanese government has authorized large transfers from taxpayers to lenders in an attempt to resolve the banking crisis in that country. In both cases (the largest banking bailouts ever made), the lenders' difficulties were preceded temporally by large falls in the value of the collateral backing the loans. (Land and unextracted oil was the collateral in Texas and Louisiana, while land was the collateral in Japan.)

This paper is based on the growing literature concerning borrower-lender relationships in the presence of enforcement limitations. For example, my paper focuses on the optimal contracting problem between a borrower and a lender, given that the former can divert the returns of his investment project. In an important recent paper, Hart and Moore (1998) analyze a richer version of this type of contracting problem. However, they do not embed it into a societal context as I do in this paper. As well, while debt emerges as an optimal contract for some parameter specifications in their model, there are always non-debt contracts that are also optimal. This is because they 
abstract from asymmetric information about the value of collateral.

Kiyotaki and Moore (1997) analyze the effects of collateral constraints on aggregate fluctuations. In their model, the value of collateral is endogenous, and this endogeneity plays a crucial role in generating large effects of collateral constraints on output. In my framework, collateral values are exogenous, and so the effects emphasized by Kiyotaki and Moore (1997) are not present.

My analysis is also related to that of Holmstrom and Tirole (1998). Their paper considers an environment in which insider financing is socially more efficient than external financing because of an agency problem. The amount of inside capital available to entrepreneurs is affected by a shock after projects are undertaken. The effects of the randomness in inside capital in their model are similar to the effects of the randomness in collateral values in my paper.

Several authors have considered optimal repayment contracts in the presence of collateral (see Lacker (1998), Rampini (1998), and Diamond (1984)). However, their approach is quite different from mine. In their models, project returns are ex-post unobservable and the value of collateral is observable. Collateral is then used as a crude screening device to determine whether project returns are high or low. There are no enforcement frictions. In my setting, project returns might well be known a priori; the contracting problem is to figure out how to force the entrepreneur to share those returns with his lenders.

There is also, of course, a vast literature concerning deposit insurance. Following Diamond and Dybvig (1983), this literature typically rationalizes deposit insurance as an optimal way for governments to get around a sequential service constraint faced by banks. ${ }^{1}$ I view my "riskycollateral" rationalization of deposit insurance as being a complement to, not a substitute for,

\footnotetext{
${ }^{1}$ See Bryant (1980) and Chari and Jagannathan (1988), among others. Smith and Wang (1998) provide a different rationalization of deposit insurance based on costly state verification in a two-period setting.

It should be noted that there is a theoretical criticism of this rationalization of deposit insurance. In Diamond and Dybvig's (1983) paper, the sequential service constraint has no explicit physical or informational foundation. When Wallace (1988) provides this kind of foundation, deposit insurance is no longer feasible.
} 
Diamond-Dybvig's "sequential-service" rationalization. As I emphasize later in the paper, in a world with both sequential service constraints and collateral shocks, deposit insurance payments would be conditioned on both withdrawal shocks (as in Diamond-Dybvig) and on collateral shocks (as in this paper).

\section{Model Specification}

In this section, I describe the basic environment, define a social contract, and write down the social planner's problem for this setting.

\section{A. Environment}

Consider a economy which has a continuum of agents. The agents are divided into three groups: borrowers, lenders, and outsiders. There are equal measures of the three groups.

Each borrower is endowed with a unit of an indivisible good called collateral. Only the borrower receives utility from consuming the collateral good with which he is endowed originally; hence, there is actually a continuum of different types of collateral goods. Each lender is endowed with one unit of divisible investment goods. Each outsider is endowed with one unit of divisible consumption goods. All agents in the economy can costlessly transform investment goods into an equivalent amount of consumption goods (but not the reverse).

Besides the unit of collateral, each borrower is endowed with a project. The project has three stages. In the first stage, an investment good is invested into the project. In the second stage, $(1-x)$ investment goods can be costlessly withdrawn from the project (where $0 \leq x \leq 1)$. In the third and final stage, the project generates $R x$ units of consumption goods, where $R$ is a constant.

A typical borrower has preferences represented by the expected value of the utility function

$$
c+v h
$$

where $(c, h)$ represent the amount of consumption and his specific collateral goods that he consumes. 
In these preferences, the parameter $v$ is random and represents the quality of the borrower's collateral. Lenders and outsiders simply maximize the expected amount of consumption goods that they eat; they receive no utility from collateral goods. ${ }^{2}$

The distribution of the collateral quality $v$ has the following form. At the beginning of the period, an aggregate shock $\pi$ is drawn from a finite set $\Pi$ according to density $f$. This aggregate shock is public information. Conditional on $\pi$, the utility parameter is independently distributed across borrowers; a borrower's $v$ equals $V$ with probability $\pi$ and equals 0 otherwise. The borrower privately observes the realization of $v$ after investment is complete.

There are three frictions in this environment. The first is that collateral quality is ex-post privately known only to the borrower. The other two frictions are enforcement limitations. In particular, after the second stage, lenders are free to withdraw any or all of their funds. After the third stage, society cannot prevent the borrower from "walking away" with the proceeds of the project. The borrower cannot expropriate the collateral good, though.

Note that society's ability to extract resources differs across agents. Outsiders are unable to walk away from any societal contract. Borrowers are able to walk away from any societal contract, but they have to lose their collateral good. Lenders are free to leave any societal arrangement at any time.

\section{B. Social Contracts}

In this environment, a social contract has five components. The first component is a function $x(\pi)$ that describes the amount of investment goods left in each borrower's project after the aggregate shock realization $\pi$. The second component is a function $c_{l}(\pi)$ that describes the amount of

\footnotetext{
${ }^{2}$ The assumption that lenders and outsiders receive no utility from collateral goods may seem overly strong. The main results of the paper extend, though, to environments in which this assumption is relaxed. The key is that lenders and the outsiders must be less willing to substitute consumption for collateral goods than are borrowers; otherwise, it becomes a matter of social indifference whether repayment is done using consumption or collateral.
} 
consumption goods consumed by each lender, given aggregate shock realization $\pi$. The third component $c_{o}(\pi)$ describes the amount of consumption goods consumed by each outsider given aggregate shock realization $\pi$.

The final two components are conditioned on the collateral quality realizations for each borrower. In particular, $c_{b}(\pi, v)$ is the amount of consumption of a borrower with utility parameter realizations $v$, given aggregate shock realization $\pi$. Finally, $\delta(\pi, v)$ is a dummy variable that indicates whether the borrower consumes his collateral good $(\delta=1)$ or does not $(\delta=0)$.

Given a social contract $\left(x, c_{l}, c_{o}, c_{b}, \delta\right)$, the sequence of events is as follows. At the beginning of the period, all the investment goods are invested in the borrowers' projects. Then, the aggregate shock is drawn; its value $\pi$ is common knowledge. At that point, $(1-x(\pi))$ investment goods are withdrawn from each borrower's project, and every borrower is left with $x(\pi)$ investment goods to run his project. Having done so, the borrowers have $R x(\pi)$ consumption goods. Each borrower privately observes his realizations of $v$ and makes an announcement $\widehat{v}$ about it. He consumes $c_{b}(\pi, \widehat{v})$ units of consumption and $\delta(\pi, \widehat{v})$ units of collateral.

The above description is what happens if all agents follow the contract. However, borrowers and lenders can defect from the contract. First, after the realization of $\pi$, but before the projects are run, any lender can leave the contract by withdrawing any or all of his investment goods. (Hence, defection provides the lender with a utility of 1.) Second, after his project is run, a borrower is allowed to opt to leave the contract. If he does so, he consumes $R x(\pi)$ consumption goods and 0 collateral goods.

As I spell out later, I interpret the social contract as follows. I think of lenders as being like bank depositors or equityholders; when they initially enter the social contract, they are implicitly depositing their investment goods with a financial intermediary. The borrowers are like entrepreneurs who want to finance a project. The outsiders are like taxpayers because they face enormous costs 
of not meeting their social obligations.

I assume throughout that

$$
R>1
$$

This means that conditional on any $\pi$, investment serves to expand the societal pie. This assumption makes it clear that any failure to invest is due to limitations on enforcement, not to any intrinsic limitations in the borrower's project.

I also assume throughout that

$$
V>R
$$

As will become clear, this guarantees that in any contract, borrowers have no incentive to walk away if their collateral quality is high.

\section{Defining Feasibility and Optimality}

In this section, I describe what social contracts are incentive-feasible: that is, incentivecompatible and physically feasible. I go on to write down a social planner's problem that characterizes the optimal social contracts from the set of incentive-feasible ones.

I define an incentive-compatible contract to be one such that for all $\pi$ and $v$, it is weakly optimal for the borrowers not to walk away, weakly optimal for the lenders not to walk away, and weakly optimal for the borrowers not to lie about their collateral realization.

Definition 1. A social contract $\left(x, c_{l}, c_{o}, c_{b}, \delta\right)$ is incentive-compatible if

$$
\begin{aligned}
c_{l}(\pi) & \geq 1 \\
c_{b}(\pi, V)+\delta(\pi, V) V & \geq R x(\pi) \\
c_{b}(\pi, 0) & \geq R x(\pi)
\end{aligned}
$$




$$
\begin{aligned}
c_{b}(\pi, V)+\delta(\pi, V) V & \geq c_{b}(\pi, 0)+\delta(\pi, 0) V \\
c_{b}(\pi, 0) & \geq c_{b}(\pi, V) .
\end{aligned}
$$

The conditions (1)-(5) require that it is weakly optimal for lenders not to walk away, borrowers not to walk away (regardless of their collateral value), and weakly optimal for borrowers not to lie (regardless of their collateral value). The Revelation Principle implies that there is no loss in generality in restricting attention to incentive-compatible social contracts. Henceforth, when I use the term "social contract", I am implicitly referring to incentive-compatible social contracts.

A main goal of this paper is to characterize optimal social contracts. By "optimal", I mean social contracts that solve the following social planner's problem:

$$
\begin{aligned}
& \max _{x, c_{b}, \delta, c_{l}, c_{o}} \sum_{\pi}\left[\pi\left\{c_{b}(\pi, V)+\delta(\pi, V) V\right\}+(1-\pi) c_{b}(\pi, 0)\right] f(\pi) \\
& \text { s.t. } \\
& \sum_{\pi} c_{o}(\pi) f(\pi) \geq 1 \\
& \sum_{\pi} c_{l}(\pi) f(\pi) \geq 1 \\
& \pi c_{b}(\pi, V)+(1-\pi) c_{b}(\pi, 0)+c_{l}(\pi)+c_{o}(\pi) \\
& \leq \quad x(\pi) R+(1-x(\pi))+1 \\
& c_{b}(\pi, V), c_{b}(\pi, 0), c_{l}(\pi), c_{o}(\pi) \geq 0 \\
& c_{l}(\pi) \geq 1 \\
& c_{b}(\pi, V)+\delta(\pi, V) V \geq R x(\pi) \\
& c_{b}(\pi, 0) \geq R x(\pi) \\
& c_{b}(\pi, V)+\delta(\pi, V) V \geq c_{b}(\pi, 0)+\delta(\pi, 0) V \\
& c_{b}(\pi, 0) \geq c_{b}(\pi, V) .
\end{aligned}
$$


In this problem, condition (7) expresses the requirement that the lenders be no worse off than autarky (ex-ante); condition (6) expresses the same restriction for the outsiders. The next condition is the physical resource constraint. The final constraints are the incentive-compatibility conditions. (Note that condition (7) is implied by condition (10).)

\section{Properties of Optimal Social Contracts}

In this section, I discuss the properties of optimal social contracts. I begin by describing the linkage between the properties of contracts in the model environment and properties of banking systems in the real world. Then, I describe under what circumstances optimal contracts satisfy these properties.

\section{A. Formalizing Institutions of Intermediation}

The purpose of this subsection is to consider different institutions in the real world and formally define their analogues in the model environment. For example, in the real world, much bank finance is done through collateralized debt contracts, in which a borrower either pays the face value of the loan to the lender, or, alternatively, transfers his collateral to the lender. Thus, I define a debt contract to be a contract such that for all $\pi$

$$
\begin{aligned}
& \delta(\pi, V)=1 \\
& c_{b}(\pi, V)<c_{b}(\pi, 0) \Rightarrow \delta(\pi, 0)=0 .
\end{aligned}
$$

Under this definition, the borrower's repayment $\left(R x(\pi)-c_{b}(\pi, V)\right)$ is implicitly treated as the face value of the loan. The definition says that the borrower gives up his collateral good if his repayment falls below the face value of the debt. Note that the face value of the debt might be contingent on the realization of the aggregate state $\pi$. 
A crucial feature of the financial landscape in most developed economies is deposit insurance. ${ }^{3}$

In the real world, this means that depositors are free to withdraw their deposits and are guaranteed to receive their promised return. This guarantee is backed by the taxpayers (although, potentially, it could be backed by an insurance company). In the model environment, this means that the lenders never want to withdraw their initial deposits, because the deposits are backed by taxes raised from the outsiders. Formally, I say that a social contract features deposit insurance if for some $\pi, c_{l}(\pi)=1$ and $c_{o}(\pi)<1$.

Finally, in some states of the world, it may be optimal for $x(\pi)=0$. If we take the view that the lenders' participation in the social contract is equivalent to their depositing money in a bank, then setting $x(\pi)=0$ is equivalent to massive withdrawals. Hence, I refer to a contract in which $x(\pi)=0$ for some $\pi$ (but not all $\pi$ ) as being one that features disintermediation ${ }^{4}$.

\section{B. Optimality of Debt Contracts}

The following proposition shows that all optimal contracts are debt contracts.

Proposition 1. Suppose that $\left\{x, c_{l}, c_{o}, c_{b}, \delta\right\}$ is an optimal social contract. Then, $\delta(\pi, V)=1$ for all $\pi$. For any $\pi$ such that $c_{b}(\pi, V)<c_{b}(\pi, 0)$, then $\delta(\pi, 0)=0$.

Proof. Suppose that $\delta(\pi, V)=0$. Then, construct a new contract by setting $\delta(\pi, V)=1$. This raises the borrowers' utility and does not violate any incentive constraints.

Now suppose that $c_{b}(\pi, V)<c_{b}(\pi, 0)$. Then, the borrower $V$ 's truth-telling constraint implies that $\delta(\pi, 0)=0$. (Note that this last implication relies only on incentive-compatibility, not on optimality.)

\footnotetext{
${ }^{3}$ In this environment, there is no real distinction between depositors and other owners of bank assets, like equityholders and debtholders. Hence, what I term "deposit insurance" in the context of the model can actually be interpreted as "bank owner" insurance. In reality, bailouts of other bank owners often occur concurrently with bailouts of bank depositors.

${ }^{4}$ Throughout, I focus on properties of efficient allocations without explicitly describing how those allocations might be achieved using decentralized trade. I conjecture that these allocations are equilibrium outcomes of trading arrangements similar to those described by Kehoe and Levine (1993) and Alvarez and Jermann (1998).
} 
The strict optimality of debt contracts relies crucially on the assumption that the collateral quality is private information to the borrower. No repayment schedule can ask the borrower to pay anything when his collateral quality is zero, or he will walk away from the contract. This creates an incentive for the borrower to claim that his collateral good is worthless. The debt contract gets around this problem by requiring the borrower to physically give up his collateral when he does not value it.

\section{First-Best Investment}

In this subsection, I describe how if $R$ is sufficiently large, then it is optimal to set $x(\pi)=1$ for all $\pi$, as is true if there are no incentive-compatibility conditions. I show when doing so requires the use of deposit insurance.

As will become clear, the key to all of the results is that while the total societal pie remains fixed at $R$, the pie that is shareable among all members of society equals $\pi R$. (The rest of the pie goes directly to borrowers with poor collateral.) In order to maximize the welfare of the borrowers, it is optimal to make the scale of project operation as large as possible (because $R>1$ ). But lenders will not be willing to do so if $\pi R<1$ unless they receive outside funds. The role of the outsiders is to provide cross-state redistribution of the shareable pie in order to get as many projects as possible off the ground.

The first proposition demonstrates that if $\pi R \geq 1$ for all $\pi$, then in any optimal contract, $x(\pi)=1$. Moreover, this can be achieved without deposit insurance.

Proposition 2. If $\min _{\pi} \pi R \geq 1$, then, in any optimal social contract, $x(\pi)=1$, and there exists an optimal social contract such that $c_{l}(\pi)=c_{o}(\pi)=1$ for all $\pi$.

Proof. Substitute the resource constraint, the lenders' participation constraint, and the outsiders' participation constraint into the planner's objective. Then, it is clear that for any contract with 
investment plan $x$, the borrower's ex-ante utility is bounded from above by

$$
B(x)=\sum_{\pi} f(\pi)\{x(\pi) R+(1-x(\pi))+\pi V\}-1 .
$$

This bound is maximized by setting $x(\pi)=1$ for all $\pi$, because $R>1$. Thus, no contract can attain a value for the planner's objective higher than

$$
B^{*}=\sum_{\pi} f(\pi)\{R+\pi V\}-1
$$

Now, consider the contract

$$
\begin{aligned}
x(\pi) & =1 \\
c_{l}(\pi) & =1 \\
c_{o}(\pi) & =1 \\
c_{b}(\pi, V) & =R-1 / \pi \text { and } c_{b}(\pi, 0)=R \\
\delta(\pi, V) & =1 \text { and } \delta(\pi, 0)=0 .
\end{aligned}
$$

The contract satisfies the social planner's constraints and attains the upper bound $B^{*}$ for the planner's objective. Hence, this contract is optimal. Moreover, any contract in which $x(\pi)<1$ for some $\pi$ achieves a utility lower than $B(x)$, which is strictly less than $B^{*}$.

The point of this proposition is that when $R$ is sufficiently high, then there is no need to use deposit insurance. The lenders are willing to finance all projects, because the borrowers can recompense them sufficiently using the proceeds of the project in the states in which the value of the collateral is sufficiently high.

More interesting is the case in which $\min _{\pi} \pi R<1$, but $\sum_{\pi} f(\pi) \pi R \geq 1$. In this case, deposit insurance is an intrinsic feature of the optimal contract. Note that this requires a non-trivial aggregate shock, because $\min _{\pi} \pi<\sum_{\pi} f(\pi) \pi$. 
Proposition 3. If $\min _{\pi} \pi R<1$ and $\sum_{\pi} f(\pi) \pi R \geq 1$ then, in any optimal contract, $x(\pi)=1$. There is no optimal contract such that $c_{o}(\pi) \geq 1$ for all $\pi$.

Proof. As in the proof of Proposition 2, any contract with investment plan $x$ achieves a value for the planner's objective that is no greater than

$$
B(x)=\sum_{\pi} f(\pi)\{R x(\pi)+(1-x(\pi))+\pi V\}-1
$$

Also, as in the proof of Proposition 2, $B(x)$ is bounded from above by

$$
B^{*}=\sum_{\pi} f(\pi)\{R+\pi V\}-1
$$

where $B(x)<B^{*}$ if $x(\pi)<1$ for some $\pi$.

Now, I construct an incentive-compatible contract in which $x(\pi)$ is equal to 1 for all $\pi$ :

$$
\begin{aligned}
x(\pi) & =1 \\
c_{l}(\pi) & =1 \\
c_{o}(\pi) & =\pi /\left[\sum_{\pi} f(\pi) \pi\right] \\
c_{b}(\pi, V) & =R-\left[\sum_{\pi} f(\pi) \pi\right]^{-1} \text { and } c_{b}(\pi, 0)=R \\
\delta(\pi, V) & =1 \text { and } \delta(\pi, 0)=0 .
\end{aligned}
$$

This contract is optimal because it attains the upper bound $B^{*}$. Moreover, any contract in which $x(\pi)<1$ for some $\pi$ must achieve a lower utility, because it is bounded above by $B(x)<B^{*}$.

We know from the resource constraint, and from the borrowers' incentive constraints, that $c_{o}(\pi)+c_{l}(\pi) \leq\{x(\pi) \pi R+(2-x(\pi))\}$. Now suppose that $\pi R<1$ in some state. It is immediate that if $c_{l}(\pi) \geq 1$ and $\left.c_{o}(\pi)\right) \geq 1$ for some $\pi$, then that $x(\pi)=0$ in that state.

Under the parametric assumptions made in the proposition, deposit insurance plays an essential role in the optimal allocation of resources. It is useful to see how deposit insurance works in 
this setting. Consider the contract described in the proof of the above proposition. We can think of the face value of the debt as being independent of $\pi$ in this case (because $R-c_{b}(\pi, V)$ is independent

of $\pi$ ). The lenders pay some fraction of their loan proceeds to the outsiders when $\pi$ is high and receive a transfer from the outsiders when $\pi$ is low. Thus, this contract features deposit insurance.

Note that the outsiders are unhappy with the lenders when $\pi$ is low (just like any insurer is unhappy when it must actually provide insurance). Given the realization of $\pi$, the lenders are making loans to the borrowers that, because of bankruptcy risk, have an expected return less than zero. Yet, the lenders make these loans because the outsiders will make up the shortfall. Given the realization of $\pi$, the outsiders would prefer to stop the lenders from making these loans - but this would be inefficient from an ex-ante point of view.

The lenders' ex-post participation constraints make deposit insurance essential. Suppose instead that the lenders faced only an ex-ante participation constraint. Then, there is an alternative contract that is optimal: $c_{o}(\pi)=1$ and $c_{l}(\pi)=\pi / \sum_{\pi} f(\pi) \pi$. Under this contract, the lenders would like to withdraw their investment goods when $\pi$ is low. Implicitly, the lenders are being prevented from doing this kind of withdrawal - they are facing a suspension. Again, while the lenders are certainly unhappy with this policy when they see a low realization of $\pi$, it is optimal from an ex-ante point of view.

\section{Optimal Disintermediation}

In this subsection, I consider how the enforcement limitations can lead to a collapse of investment. For example, in the next proposition, I demonstrate that it may be optimal to have no investment in any state of the world - even though $\pi R>1$ for all $\pi$.

Proposition 4. If $\max _{\pi} \pi R<1$, in any social contract that satisfies the social planner's constraints, $x(\pi)=0$ for all $\pi$. 
Proof. From the nonnegativity of $c_{b}(\pi, V)$, the resource constraint implies that

$$
x(\pi) \pi R+2-x(\pi) \geq c_{l}(\pi)+c_{o}(\pi)
$$

Summing over $\pi$ demonstrates that

$$
2>2-\sum x(\pi)\{1-\pi R\} f(\pi) \geq \sum\left[c_{l}(\pi)+c_{o}(\pi)\right] f(\pi)
$$

which means that either the outsiders' or the lenders' participation constraint is violated.

This proposition demonstrates that if collateral is sufficiently poor, investment is not Paretoimproving. The logic is best illustrated by considering the extreme case where the borrower has no collateral at all. In that case, the borrower extracts all the proceeds from the investment. There is no way to transfer the returns of the project to the lenders or the outsiders. Hence, investment is not Pareto improving - even though it does expand aggregate output.

The next proposition shows that if $\max _{\pi} \pi R>1$ and $\sum_{\pi} f(\pi) \pi R<1$, then the optimal contract features disintermediation.

Proposition 5. Suppose that $\max _{\pi} \pi R>1, \sum_{\pi} f(\pi) \pi R<1$, and there exists $\pi^{*}$ such that $\sum_{\pi \geq \pi^{*}} f(\pi)\{\pi R-1\}=0$. Then, in any optimal contract, $x(\pi)=1$ if $\pi \geq \pi^{*}$ and $x(\pi)=0$ if $\pi<\pi^{*}$. Also, in any contract, if $x(\pi)=1$ and $\pi R<1$, then $c_{o}(\pi)<1$.

Proof. See the appendix.

The intuition behind this proposition is simple. If $\sum_{\pi} \pi R f(\pi)<1$, then it is not possible to set $x(\pi)=1$ for all $\pi$ without driving the outsiders below their ex-ante participation constraints. On the other hand, because $\max _{\pi} \pi R>1$, it is certainly possible to set $x(\pi)=1$ in at least one state. It follows that any optimal contract features disintermediation.

Note that the requirement in the proposition that there exists $\pi^{*}$ such that $\sum_{\pi \geq \pi^{*}} f(\pi)\{\pi R-$ $1\}=0$ would automatically be satisfied in a world in which $f$ is continuous over an interval $\Pi$. 
Assuming that this restriction is satisfied in the finite support case simplifies the structure of the optimal contract.

Proposition 5 identifies parameter settings such that the optimal arrangement features stochastic aggregate output, even though project returns are deterministic. If the realization of $\pi$ is low enough that $x(\pi)$ is set equal to 0 , then aggregate output equals 2 . If $\pi$ is high enough that $x(\pi)$ is set equal to 1 , then aggregate output equals $(1+R)$ (which is the maximal output possible in the economy).

\section{Discussion}

In this section, I discuss some aspects of the model and results.

\section{A. Comparison with Diamond-Dybvig}

I emphasize in this paper that bank loans are different from other forms of entrepreneurial finance because repayment is enforced via risky collateral. Diamond-Dybvig (1983) emphasizes two other aspects of banks: the random need for liquidity on the part of bank depositors and the banks' sequential service constraint. Specifically, they assume that a random fraction of lenders need to consume before projects are actually run. The lenders' type (consume early or consume late) is private information to the lender. When a given lender shows up at the bank, the bank faces a sequential service constraint, so that it must make a payment to an early withdrawer before the number of early withdrawers is actually observed.

It is interesting to consider what happens if these two extra ingredients (privately observed preference shocks and sequential service) are added to the model in this paper. In this augmented environment, the optimal arrangement has two types of deposit insurance. The first operates as I have described above: outsiders insure lenders against aggregate collateral fluctuations.

The second type of deposit insurance operates as in Diamond-Dybvig. By assumption, the 
government does not face the sequential service constraint. Then, after all early withdrawers have shown up at the bank, the government taxes them and transfers these taxes back to the bank. Two features of this latter system are crucial. The first is that the size of the tax is based on the number of early withdrawers. It is this information that gives the government an advantage over the banking system. The second is that the taxes are imposed directly on early withdrawers. It is this feature that serves to deter agents who don't need to consume early from acting as if they do.

We can summarize this analysis as follows. In a world with both the frictions described in this paper and the frictions described in Diamond-Dybvig, there are two types of deposit insurance. Lenders are insured against aggregate collateral shocks (as in my model) and they are insured against withdrawal shocks (as in Diamond-Dybvig's model). The first type of insurance must make use of the resources of outsiders, while it is important that the second type of insurance does not. Actual implementations of deposit insurance (as in the S \& L crisis) more closely resemble the first type of insurance.

\section{B. Moral Hazard}

It is generally believed that deposit insurance creates a severe moral hazard problem. The essence of the problem is as follows. Suppose a government or a private insurer guarantees depositors a fixed return; however, the government/insurer cannot observe project choice on the part of the banks. Then, the bailout program provides an incentive for banks to ignore downside risk when choosing among projects.

This kind of moral hazard problem does not appear in my model. It is important to understand, though, that this paper does not purport to rationalize blanket deposit guarantees. Rather, it rationalizes insurance of depositors against a particular type of shock: aggregate movements in the value of collateral. As long as the aggregate value of collateral is publicly observable and cannot be influenced by a given depositor, this kind of insurance is immune to moral hazard or adverse 
selection problems. (Similarly, in Diamond and Dybvig (1983), deposit insurance is really insurance against aggregate withdrawal shocks and so is immune to moral hazard considerations.)

\section{Stochastic Returns}

Throughout the paper, I assume that project returns are deterministic. But this is merely to simplify the exposition. In particular, suppose that $R$ is stochastic across individuals and the random variable $\pi$ now represents an aggregate state that indexes the joint cross-sectional distribution of $(R, v)$. It is straightforward to prove that in any optimal allocation, $x\left(\pi^{*}\right)=0$ for all $\pi^{*}$ such that $E\left(R \mid \pi=\pi^{*}\right)<1$.

This result implies that the relevant support of $\pi$ is $P=\left\{\pi^{*} \mid E\left(R \mid \pi=\pi^{*}\right) \geq 1\right\}$. Given this fact, it is easy to derive analogs of the above Propositions. For example, the analog of Proposition 3 would say: Suppose that $E(R \pi \mid \pi \in P) \geq 1$ and there exists $\pi^{*} \in P$ such that $\pi^{*} E\left(R \mid \pi=\pi^{*}\right)<1$. Then, any optimal allocation features deposit insurance and has $x(\pi)=1$ for all $\pi$ in $P$.

\section{Conclusions}

This paper advances a new view of deposit insurance. In my model, deposit insurance is, in fact, insurance. Under the optimal system, there are states of the world in which it is common knowledge that all possible loans are unprofitable ones, in the sense that their expected repayments do not cover their initial outlay. Nonetheless, because the projects themselves are socially desirable, it is efficient for lenders to make the loans and for taxpayers to cover the lenders' losses. Indeed, if the environment were dynamic, and the collateral shocks were persistent, this pattern of taxpayers' backing up bad loans might continue for many periods.

Ex-ante, the taxpayers were happy to sign up with the deposit insurance system because the transfers that they received from lenders/borrowers balanced their taxes. After a severe collateral shock hits, though, taxpayers are ex-post unhappy. From their point of view, it looks like the system 
is hemorrhaging (especially if collateral shocks are persistent), because they have to pay large taxes to keep lenders afloat. But the unhappiness of taxpayers in this situation is exactly the same as that experienced by an insurance company after a hurricane hits the Atlantic coast. In particular, it is not a sign that the deposit insurance should be eliminated or dramatically altered.

The paper also provides a novel rationale for systemic disintermediations. Suppose that ex-ante bankruptcy risk is severe $\left(\Sigma_{\pi} f(\pi) \pi R<1\right)$. Then, borrowers can expropriate so much of their projects' payoffs that depositors are unwilling to participate in any social contract in which full investment always takes place $(x(\pi)=1$ for all $\pi)$. In order to make sure that the borrowers' projects get run in at least some states of the world (ones with high values of $\pi$ ), Proposition 5 shows that it is optimal to promise to return their funds to them in other states of the world (low values of $\pi)$.

Withdrawing funds in this way appears bad, because it causes a complete collapse of investment in the economy. Moreover, even though real returns have not (necessarily) changed, real output falls. Nonetheless, what appear to be banking panics are actually part of an efficient intermediation system, given sufficient collateral risk. 


\section{Appendix: Proof of Proposition 5}

It is obvious that for any optimal contract, the lenders' participation constraint, the outsiders' participation constraint, and the resource constraint must be satisfied with equality (just give any slack resources to the borrower). Let $x$ be the investment policy of some contract which satisfies the lenders' interim participation constraints with equality, the outsiders' ex-ante participation constraint with equality, the borrowers' walk-away constraints, and the borrowers' non-negativity constraints. This contract must satisfy the constraint

$$
\sum_{\pi} f(\pi)[x(\pi) \pi R+(1-x(\pi))] \geq 1
$$

Substituting the resource constraint and the lenders'/outsiders' participation constraints into the objective, the utility of any contract which satisfies all of these constraints with equality is given by $B(x)$, where

$$
B(x)=\sum_{\pi} f(\pi)\{R x(\pi)+(1-x(\pi))+V \pi\}-1 .
$$

This means that the optimal contract cannot attain a higher value than the solution to the maximization problem $P$ :

$$
\begin{aligned}
& \max _{x} B(x) \\
& \text { s.t. } \\
& \sum_{\pi} f(\pi)[\pi R x(\pi)+(1-x(\pi))] \geq 1 \\
& 1 \geq x(\pi) \geq 0 .
\end{aligned}
$$

Any solution to $P$ satisfies the first order conditions:

$$
\begin{aligned}
f(\pi)\{R-1+\lambda(\pi R-1)\}-m_{1}(\pi)+m_{0}(\pi) & =0 \\
\lambda\left\{\sum_{\pi} f(\pi)[\pi R x(\pi)+(1-x(\pi))]-1\right\} & =0
\end{aligned}
$$




$$
\begin{aligned}
m_{1}(\pi)\{1-x(\pi)\} & =0 \\
m_{0}(\pi) x(\pi) & =0 \\
\lambda, m_{1}, m_{0} & \geq 0 .
\end{aligned}
$$

Here, $\lambda$ is the multiplier on the constraint $\sum_{\pi} f(\pi)\left[\pi x(\pi) R+(1-x(\pi)] \geq 1, m_{1}(\pi)\right.$ is the multiplier on the constraint $x(\pi) \leq 1$, and $m_{0}(\pi)$ is the multiplier on the constraint $x(\pi) \geq 0$.

If $\lambda=0$, then $m_{1}(\pi)>0$ for all $\pi$, and so $x(\pi)=1$ for all $\pi$. But this implies that $\sum_{\pi} f(\pi) \pi R<1$, which is outside the constraint set of $P$. Hence, $\lambda>0$.

The first FOC then implies that any solution to $P$ has the form $x^{*}(\pi)=1$ for all $\pi>\pi_{c}$ and $x^{*}(\pi)=0$ for all $\pi<\pi_{c}$, where $\left(R-1+\lambda\left(\pi_{c} R-1\right)\right)=0$. In order to satisfy the resource constraint, this means that the unique $x^{*}$ that solves $P$ is one in which $x^{*}(\pi)=1$ for all $\pi \geq \pi^{*}$ and $x^{*}(\pi)=0$ for all $\pi<\pi^{*}$, where $\pi^{*}$ is defined so as to satisfy the expression $\sum_{\pi \geq \pi^{*}} f(\pi)(\pi R-1)=0$.

This analysis tells us that if there is any element of the planner's constraint set with an investment plan $x^{*}$, all optimal contracts must have this investment plan. To complete the proof, we need to construct an element of the planner's constraint set such that the investment plan is $x^{*}$. But the following contract does this:

$$
\begin{aligned}
x(\pi) & =x^{*}(\pi) \\
c_{l}(\pi) & =1 \\
c_{o}(\pi) & =x^{*}(\pi) \pi R+\left(1-x^{*}(\pi)\right) \\
c_{b}(\pi, V) & =0 \text { and } c_{b}(\pi, 0)=R x^{*}(\pi) \\
\delta(\pi, V) & =1 \text { and } \delta(\pi, 0)=0 .
\end{aligned}
$$




\section{References}

[1] Alvarez, F., and Jermann, U., 1998, "Asset Pricing When Risk Sharing Is Limited by Default." Manuscript, University of Chicago.

[2] Bryant, J., 1980, "A Model of Reserves, Bank Runs, and Deposit Insurance," Journal of Banking and Finance 4, 335-44.

[3] Chari, V. V., and Jagannathan, R., 1988, "Banking Panics, Information, and Rational Expectations Equilibrium," Journal of Finance 43, 749-761.

[4] Diamond, D., and Dybvig, P., 1983, "Bank Runs, Deposit Insurance, and Liquidity," Journal of Political Economy 91, 401-19.

[5] Diamond, D., 1984, "Financial Intermediation and Delegated Monitoring," Review of Economic Studies 51, 393-414.

[6] Hart, O., and Moore, J., 1998, "Default and Renegotiation: A Dynamic Model of Bank Debt," Quarterly Journal of Economics 113, 1-41.

[7] Holmstrom, B., and Tirole, J., 1998, "Private and Public Supply of Liquidity," Journal of Political Economy 106, 1-40.

[8] Kehoe, T., and Levine, D., 1993, "Debt-Constrained Asset Markets," Review of Economic Studies 60, 865-888.

[9] Kiyotaki, N., and Moore, J., 1997, "Credit Cycles," Journal of Political Economy 105, 211-48.

[10] Lacker, J., 1998, "Collateralized Debt as an Optimal Contract," Federal Reserve Bank of Richmond working paper. 
[11] Rampini, A., 1998, "Default Correlation and Systemic Risk in Economies with Private Information," University of Chicago working paper.

[12] Smith, B., and C. Wang, 1998, "Repeated Insurance Relationships in a Costly State Verification Model: With an application to deposit insurance," Journal of Monetary Economics 42, 207-40.

[13] Wallace, N., 1988, "Another Attempt to Explain an Illiquid Banking System: The Diamond and Dybvig Model With Sequential Service Taken Seriously," Federal Reserve Bank of Minneapolis Quarterly Review 12 (Fall), 3-16. 